\title{
Wound Healing in Normal and Diabetic Chinese Hamsters
}

\author{
E. J. Weringer and E. R. Arquilla \\ Department of Pathology, University of California Irvine, Irvine, USA
}

Summary. Wound healing was examined in normal and diabetic, non-ketotic Chinese hamsters by morphological and morphometric methods. Dermal, perforating wounds were made in the ears of the hamsters and the response to injury was evaluated in tissue biopsies. The response in normal hamsters was characterized by vascular and cellular migration and pronounced infiltration of polymorphonuclear leukocytes into the area closest to the wound (zone 1). The transition region (zone 2) between wounded and non-wounded tissue was infiltrated primarily by fibroblasts and capillaries. In wounds from diabetic hamsters, $8 \mathrm{~h}$ after injury, there was less cellular infiltration (fibroblasts 49\%, polymorphonuclear leukoytes $48 \%$ of control) and vascular proliferation ( $47 \%$ of control). In the late phase of healing ( $16 \mathrm{~h}$ after injury) the vascular ( $87 \%$ of control) and polymorphonuclear leukocyte $(103 \%)$ responses in diabetic wounds were not significantly different from control in zones 1 and 2. Wounds from diabetic hamsters also showed considerable oedema ( $143 \%$ of control) in zones 1 and 2 , which was accompanied by vascular degeneration and necrosis. At $16 \mathrm{~h}$ the collagen content of diabetic wounds was also decreased (54\% of control). Increased oedema with reduced vascular proliferation and cellular infiltration in the early healing period characterises the response to injury in the diabetic Chinese hamster.

Key words: Wound healing, spontaneous diabetes, Chinese hamster, oedema, injury, morphometry.

The diabetic syndrome in the Chinese hamster, Cricetulus griseus, results from a homozygous recessive trait $[1,2]$ and is characterised by hyperphagia [3] and early onset of hyperglycaemia and glycosuria [4].
Strains are classifed as non-diabetic (no glycosuria and no diabetic litter mates for $10-15$ generations), non-ketotic diabetic $(>2 \mathrm{~g} / 100 \mathrm{ml}$ glycosuria without ketonuria) and ketotic diabetic ( $>2 \mathrm{~g} / 100 \mathrm{ml}$ glycosuria and ketonuria). Morphological studies have revealed pathological changes and lesions consistent with the diabetic state, such as abnormal glycogen deposits in the retina [5], pancreatic islets [6], kidney tubules [5] and lesions in the aortic intima [7]. The progression of the syndrome is accompanied by decreased plasma and pancreatic insulin [8], ultimately leading to an increased mortality among the more severly diabetic animals. The Chinese hamster offers an optimally suitable test animal to examine wound healing in spontaneous insulin dependent diabetes.

Diabetic alloxan-C57B 1/6 mice have been shown to have an impaired healing response characterised by increased oedema and decreased cellular and vascular proliferation into the wound [9]. The morphological changes were reversed after insulin treatment of the diabetic mice [10]. These studies in mice suggest that the effect of insulin on growth, thus modulating the cellular and vascular events in wound healing, may be suppressed in diabetes and further, that decreased insulin levels in diabetes may be a cause of the impaired healing response. The present study was designed to examine this postulate in the spontaneously diabetic Chinese hamster.

\section{Materials and Methods}

\section{Experimental Animals}

Thirty Chinese hamsters (17 normal and 13 diabetic) were studied. Adult male or female diabetic and non-diabetic siblings of the same sex, age and body weight were generously supplied by the Upjohn Colony (Kalamazoo, Michigan) through the courtesy of Dr. G. Gerritsen. The animals were divided into two groups according 
Table 1. Fasting and non-fasting blood glucose, body weight, urine glucose and ketone levels of control and diabetic Chinese hamsters

\begin{tabular}{|c|c|c|c|c|c|}
\hline & \multicolumn{2}{|c|}{$\begin{array}{l}\text { Blood Glucose } \\
(\mathrm{mmol} / \mathrm{l})\end{array}$} & \multirow[t]{2}{*}{$\begin{array}{l}\text { Weight } \\
\text { (g) }\end{array}$} & \multirow{2}{*}{$\begin{array}{l}\text { Urinary } \\
\text { glucose } \\
(\mathrm{mmol} / \mathrm{l})\end{array}$} & \multirow[t]{2}{*}{$\begin{array}{l}\text { Urinary } \\
\text { ketones }\end{array}$} \\
\hline & fasting & $\begin{array}{l}\text { non- } \\
\text { fasting }\end{array}$ & & & \\
\hline $\begin{array}{l}\text { Control } \\
(n=17)\end{array}$ & $\begin{array}{r}4.94 \\
\pm 0.06\end{array}$ & $\begin{array}{r}10.17 \\
\pm 0.44\end{array}$ & $\begin{array}{r}29.7 \\
\pm 0.9\end{array}$ & 0 & 0 \\
\hline $\begin{array}{l}\text { Non-ketotic } \\
\text { diabetic } \\
(n=13)\end{array}$ & $\begin{array}{r}12.67 \\
\pm 1.22^{\mathrm{a}}\end{array}$ & $\begin{array}{r}20.44 \\
\pm 0.61^{\mathrm{a}}\end{array}$ & $\begin{array}{r}29.7 \\
\pm 0.8\end{array}$ & $>111$ & 0 \\
\hline
\end{tabular}

Urinary glucose and ketone levels were assessed with Ketostix and Diastix. Values are expressed as mean \pm SEM.

${ }^{a}$ Significantly greater $(p<0.001)$ than corresponding value for control hamsters

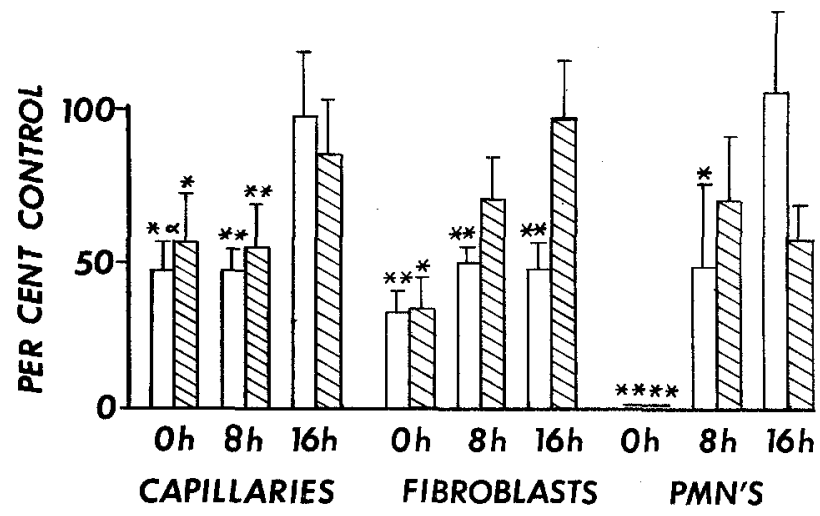

Fig. 1. Vascular and cellular response to injury in wounds from diabetic Chinese hamsters. Percentage wound volume occupied by vascular and cellular components (capillaries, fibroblasts, polymorphonuclear leucocytes, PMN). Values are expressed as percentage of control. * $p<0.05$;** $p<0.01$ compared with control hamsters. $\square=$ Zone $1 \mathbb{N}=$ Zone 2

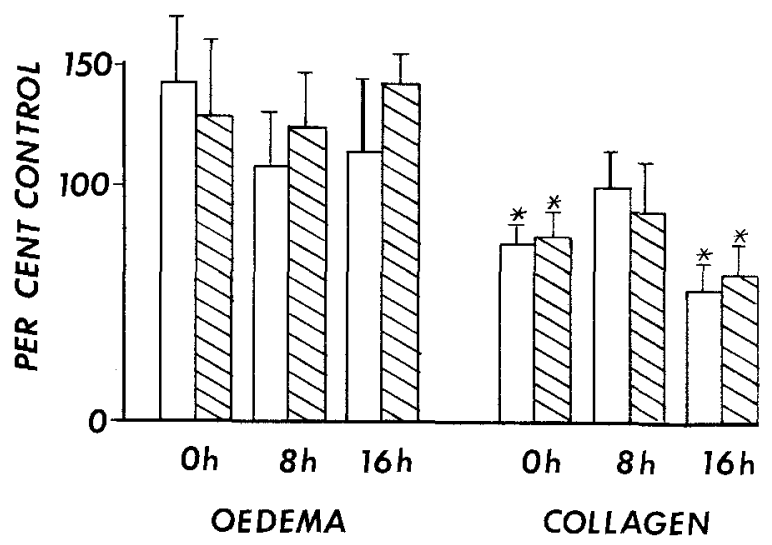

Fig. 2. Response of extracellular components to injury in wounds from diabetic Chinese hamsters. Percentage wound volume occupied by collagen and oedema fluid. Values are expressed as percentage of control. * significantly different from control $p<0.05$. $\square=$ Zone $1 \$$ Zone 2 to blood glucose, urine glucose and urine ketone levels. Group 1: normal hamsters $(n=17), 8-15$ months of age, consistently aglycosuric and derived from aglycosuric lines for the past 10-15 generations. Group 2: non-ketotic diabetic hamsters $(n=13)$ 9-12 months of age, non-ketonuric with consistent hyperglycaemia and $>2 \mathrm{~g} / 100 \mathrm{ml}$ glycosuria. The animals were housed individually and fed freely on Purina mouse breeder pellets (lipid content 12\%) and water. Fasting blood glucose was determined (autoanalyserHoffman method) on each animal at the Upjohn colony before shipping, and non-fasting blood glucose was determined (YSI glucose analyser, Yellow Springs, Ohio) before wounding on samples obtained by orbital puncture. Urinary glucose and ketones were determined using Ketostix and Diastix (Ames, Elkart, Indiana) (Table 1). The animals were matched according to weight and divided into experimental groups before wounding.

\section{Wounding of Experimental Animals}

Before wounding the hamsters were lightly anaesthetised with ether. Each ear was then sponged with $70 \%(\mathrm{v} / \mathrm{v})$ ethanol and placed over a light source to locate the vascular bed. Care was exercised to avoid damage to any major vessel during the wounding process. Two circular, perforating wounds were made in each ear with a $1.0 \mathrm{~mm}$ dermal trephine. The wounds were biopsied 0 (time of injury), 2, 4, 8 and $16 \mathrm{~h}$ later and processed for light and electron microscopy as previously described [9]. Morphological analyses of the wounds from normal and diabetic Chinese hamsters were made on samples taken from a pool of 300 blocks from the 30 experimental animals (five blocks per animal).

\section{Morphometry}

The relative volumes occupied by the major cellular and extracellular components present in the wounds from the 0,8 and $16 \mathrm{~h}$ biopsies were quantitated by a modification of the methods of Weibel et al. [11] and Wahl et al. [12]. A $10 \mathrm{~mm}$ square reticle with $1.0 \mathrm{~mm}$ line intervals was inserted into the eyepiece of an American Optical series 110 microscope and structures lying under the points of intersection were counted. Half-micron tissue sections were cut on a DuPont-Sorvall MT2-B ultratome, stained with methylene blueAzure II and examined under oil at a magnification of $\times 1200$. The wound area quantitated was divided into two zones; zone 1: $100 \mu \mathrm{m}$ area of wound including the wound edge and zone 2 : transition zone $100 \mu \mathrm{m}$ wide from zone 1 to uninjured tissue. The tissue components quantitated were capillaries, polymorphonuclear leukocytes, fibroblasts, oedema and collagen. Oedema was defined as that area devoid of visible tissue components but within the defined zones. Fifteen slides from 50 different tissue blocks were randomly selected and quantitated per time point in a double-blind design and the mean \pm SEM was determined by a multiple group T-test (Tukey's test).

\section{Results}

\section{Morphometric Studies}

The vascular and cellular response to injury is illustrated in Table 2 and Figure 1. In the diabetic, capillary volume was significantly less than the control at the time of injury in both zones 1 and 2 . This volume remained decreased up to $8 \mathrm{~h}$ after injury. By $16 \mathrm{~h}$, the capillary response approached control levels. Similar 
Table 2. Percentage volume occupied by wound components from control and diabetic Chinese hamsters

\begin{tabular}{lllllll}
\hline Time & & Capillaries (\%) & $\begin{array}{l}\text { Fibroblasts } \\
(\%)\end{array}$ & $\begin{array}{l}\text { Polymorpho- } \\
\text { nuclear } \\
\text { leukocytes } \\
(\%)\end{array}$ & $\begin{array}{l}\text { Oedema } \\
(\%)\end{array}$ & $\begin{array}{l}\text { Collagen } \\
(\%)\end{array}$ \\
\hline $0 \mathrm{~h}$ & & & & & & \\
Zone 1 & Control & $6.5 \pm 2.8^{\mathrm{a}}$ & $9.7 \pm 1.1^{\mathrm{b}}$ & $0.5 \pm 0.32^{\mathrm{b}}$ & $23.7 \pm 3.6$ & $44.6 \pm 3.1^{\mathrm{a}}$ \\
& Diabetic & $3.1 \pm 0.8$ & $3.1 \pm 0.8$ & $0.0 \pm 0.0$ & $33.8 \pm 6.5$ & $32.8 \pm 3.2$ \\
Zone 2 & Control & $7.5 \pm 1.6^{\mathrm{a}}$ & $10.9 \pm 2.3^{\mathrm{a}}$ & $0.4 \pm 0.22^{\mathrm{b}}$ & $21.8 \pm 2.6$ & $45.1 \pm 3.2^{\mathrm{a}}$ \\
& Diabetic & $4.3 \pm 1.4$ & $3.8 \pm 0.9$ & $0.0 \pm 0.0$ & $27.7 \pm 6.4$ & $34.5 \pm 3.6$ \\
\hline $8 \mathrm{~h}$ & & & & & & \\
Zone 1 & Control & $5.9 \pm 0.9^{\mathrm{b}}$ & $8.3 \pm 1.2^{\mathrm{b}}$ & $7.4 \pm 2.9^{\mathrm{a}}$ & $24.1 \pm 4.3$ & $33.1 \pm 2.9$ \\
& Diabetic & $2.8 \pm 0.4$ & $4.1 \pm 0.4$ & $3.5 \pm 2.1$ & $25.8 \pm 5.6$ & $33.6 \pm 4.5$ \\
Zone 2 & Control & $7.0 \pm 1.1^{\mathrm{b}}$ & $6.5 \pm 0.9$ & $2.6 \pm 1.2$ & $30.3 \pm 4.5$ & $28.3 \pm 3.4$ \\
& Diabetic & $3.9 \pm 0.9$ & $4.6 \pm 1.0$ & $1.8 \pm 1.7$ & $37.3 \pm 7.5$ & $24.8 \pm 5.6$ \\
\hline 16h & & & & & & \\
Zone 1 & Control & $5.4 \pm 0.4$ & $6.9 \pm 1.4^{\mathrm{b}}$ & $9.6 \pm 2.5$ & $18.6 \pm 7.6$ & $37.8 \pm 5.0^{\mathrm{a}}$ \\
& Diabetic & $7.1 \pm 1.5$ & $3.2 \pm 0.5$ & $11.8 \pm 2.4$ & $21.1 \pm 5.7$ & $20.4 \pm 4.7$ \\
Zone 2 & Control & $5.1 \pm 2.2$ & $5.3 \pm 0.8$ & $3.5 \pm 1.1$ & $25.3 \pm 9.3$ & $41.3 \pm 7.0^{\mathrm{a}}$ \\
& Diabetic & $4.4 \pm 0.9$ & $5.8 \pm 0.9$ & $2.0 \pm 0.4$ & $36.2 \pm 2.9$ & $26.2 \pm 4.9$ \\
\hline
\end{tabular}

Results expressed as mean values \pm SEM. $\quad{ }^{a} p<0.05$ diabetic versus control; ${ }^{b} p<0.01$ diabetic versus control.

observations were made on examination of the cellular response. Fibroblasts were significantly decreased in zones 1 and 2 of wounds in the diabetic hamsters at injury when compared with controls and remained lowered up to $8 \mathrm{~h}$ after injury. At $16 \mathrm{~h}$, there was an increase in fibroblasts in zone 2, most distant from the injury, but no change in zone 1 , the immediate site of injury.

In the diabetic hamsters, polymorphonuclear leukocytes were not detectable at injury, but increased during the first $8 \mathrm{~h}$. However, leukocytes in zone 1 of diabetic wounds at $8 \mathrm{~h}$ were significantly less than observed in zone 1 of control wounds. In the adjacent area (zone 2) more leukocytes were detected at $8 \mathrm{~h}$. By $16 \mathrm{~h}$ more leukocytes were present in both zones.

The volumes occupied by oedema fluid and collagen in the wound are shown in Figure 2. The wounds from diabetic hamsters at the time of injury showed more oedema than the controls and oedema volume remained elevated in the diabetic wounds up to $8 \mathrm{~h}$ after wounding. In contrast, the volume of collagen in the diabetic wounds was significantly $(p<0.05)$ reduced at injury when compared with control. A slight increase was observed at $8 \mathrm{~h}$, but by $16 \mathrm{~h}$ the value was still significantly below control. Overall, collagen was therefore reduced in the diabetic animals and did not respond to the injury stimulus.

\section{Morphological Studies}

Normal and Diabetic Hamsters. At the time of wounding $(0 \mathrm{~h})$ skin biopsies from control hamsters revealed a dense supporting network of collagen surrounded by capillaries, macrophages, fibroblasts and small nerve bundles (Fig. 3 a). By contrast, biopsies from diabetic hamsters at $0 \mathrm{~h}$ had much extracellular oedema surrounding dermal connective tissue which was comprised of few cellular elements (capillaries, fibroblasts, macrophages) and collagen (Fig. 3 b).

Within $4 \mathrm{~h}$ after injury, the control wounds were heavily infiltrated with polymorphonuclear leukocytes, fibroblasts and macrophages. In many of the fibroblasts the cytoplasmic organelles were organised with a central Golgi zone surrounded by mitochondria and rough endoplasmic reticulum (Fig. $4 \mathrm{a}$ ).

In diabetic wounds at $4 \mathrm{~h}$ the most striking change was in the capillaries where degenerative changes were marked by the appearance of myelin figures in the nucleus, and disruption of the capillary wall. Similarly many fibroblasts contained cytoplasmic irregularities in the form of dense bodies and large clusters of lysosomes (Fig. 4b), features not compatible with protein secreting cells. A decrease in polymorphonuclear leukocytes, fibroblasts and macrophages at $8 \mathrm{~h}$ after injury was accompanied by a increase in tissue oedema.

By $16 \mathrm{~h}$, oedema was the striking feature in diabetic wounds, with many disrupted and degenerated cellular elements observed around the dissolving capillary structures (Fig. 5b). Wounds from diabetic hamsters did not contain any immature capillary structures at any of the time points examined.

Cellular infiltration and collagen density were the prominent feature at $8 \mathrm{~h}$ after injury in wounds from 

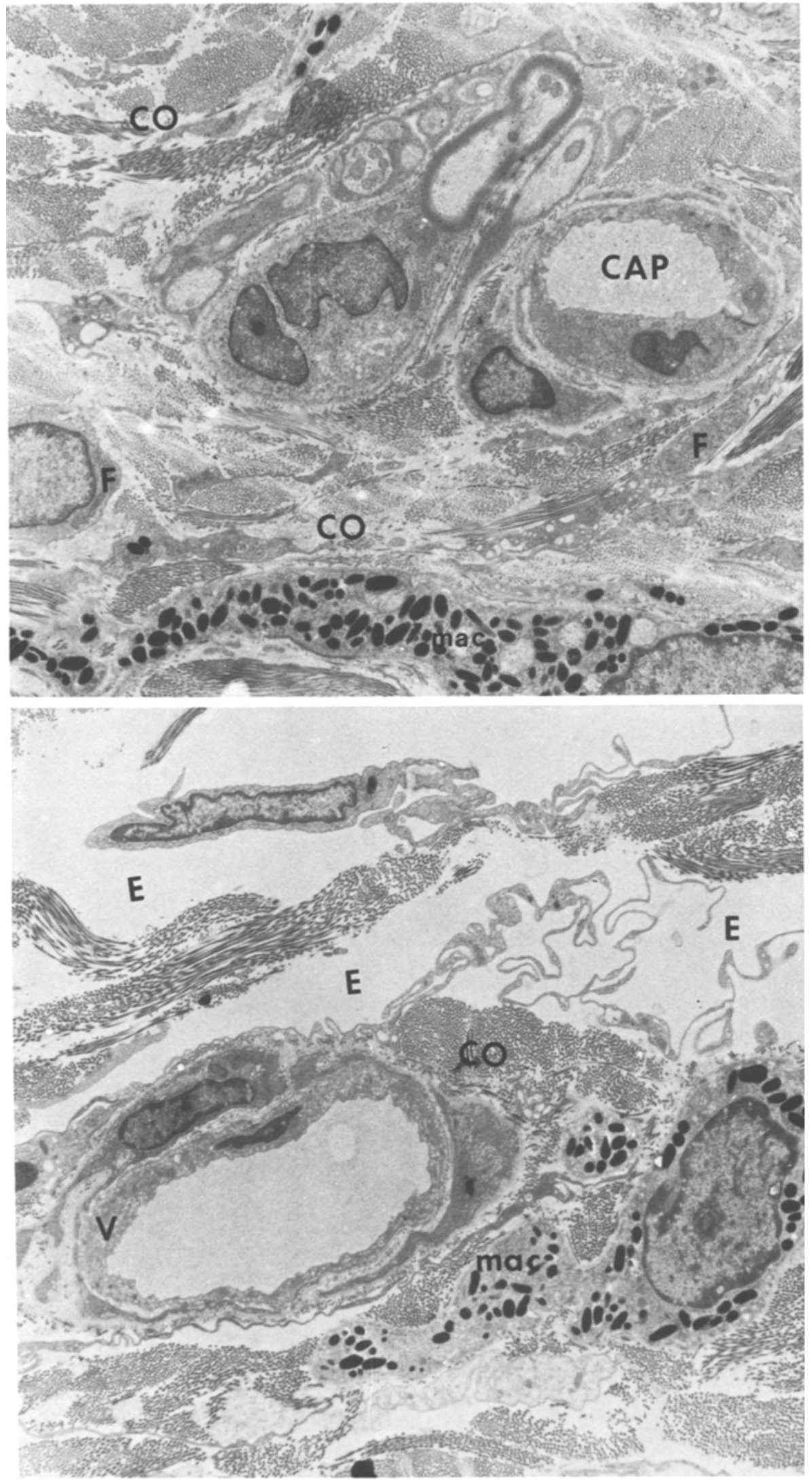

Fig. 3. a Wound edge from a control hamster at the time of injury $(0 \mathrm{~h})$. Dermal tissue contains collagen $(C O)$, capillary $(C A P)$, macrophage $(m a c)$ and fibroblast $(F) . \times 8500$. b Wound edge from a diabetic hamster at injury $(0 \mathrm{~h})$. Dermal tissue contains small venule $(V)$, macrophage (mac), collagen $(C O)$ and large area of interstitial oedema $(E) . \times 8000$ 

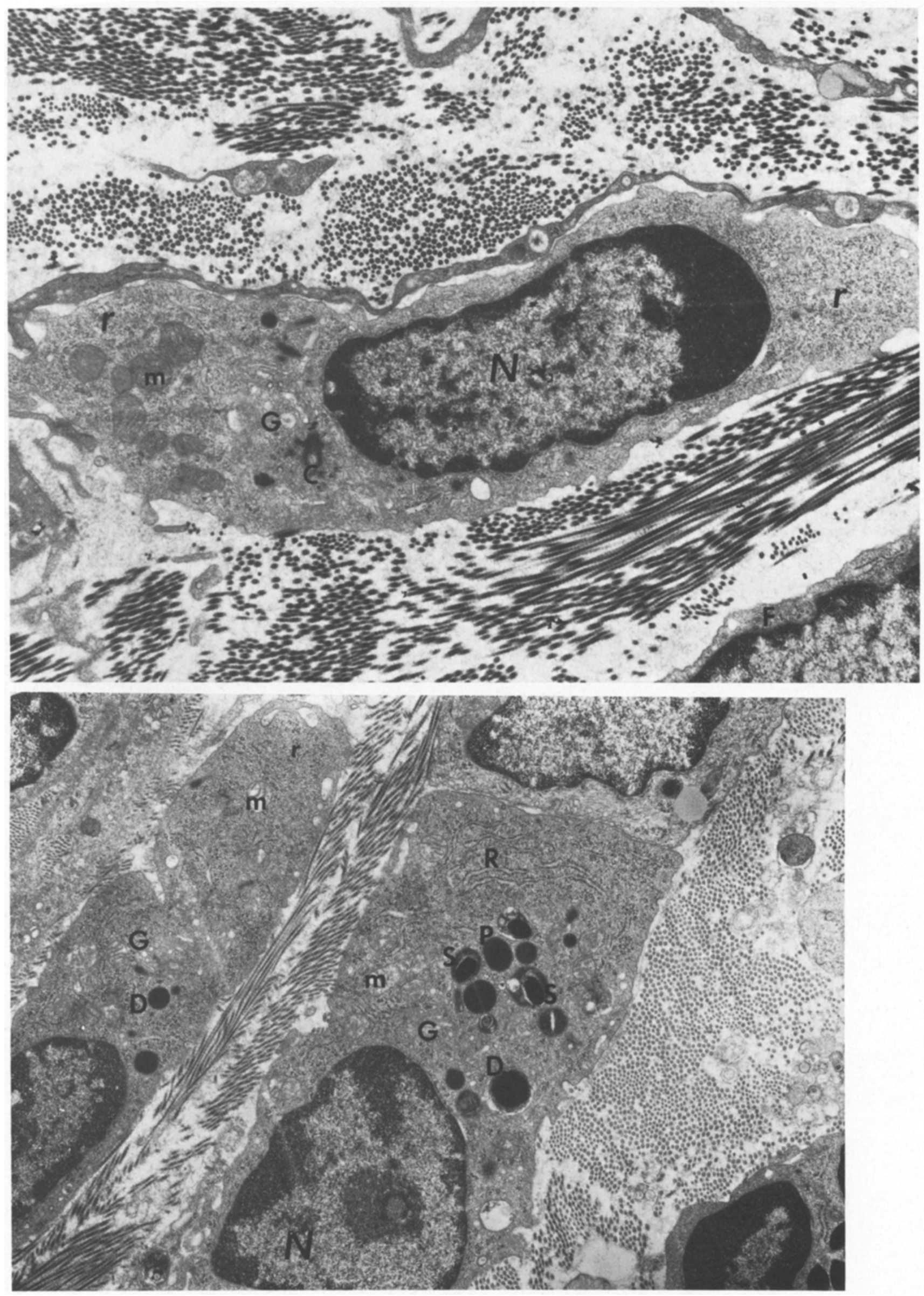

Fig. 4. a Fibroblast observed in the wound edge from a control hamster 4 h after injury. Cytoplasm contains mitochondria ( $m$ ), free ribosomes $(r)$, Golgi material $(G)$ capping the nucleus $(N)$, centriole $(C)$, and rough endoplasmic reticulum. Sections of adjacent fibroblasts $(F)$ are seen. $\times 10,700 . b$ Fibroblasts in the wound from a diabetic hamster $4 \mathrm{~h}$ after injury. Cytoplasm contains free ribosomes $(r)$, rough endoplasmic reticulum $(R)$, mitochondria $(m)$, Golgi $(G)$, and dense bodies $(D)$ associated with primary $(P)$ and secondary $(S)$ lysosomes. Nucleus $(N)$. 

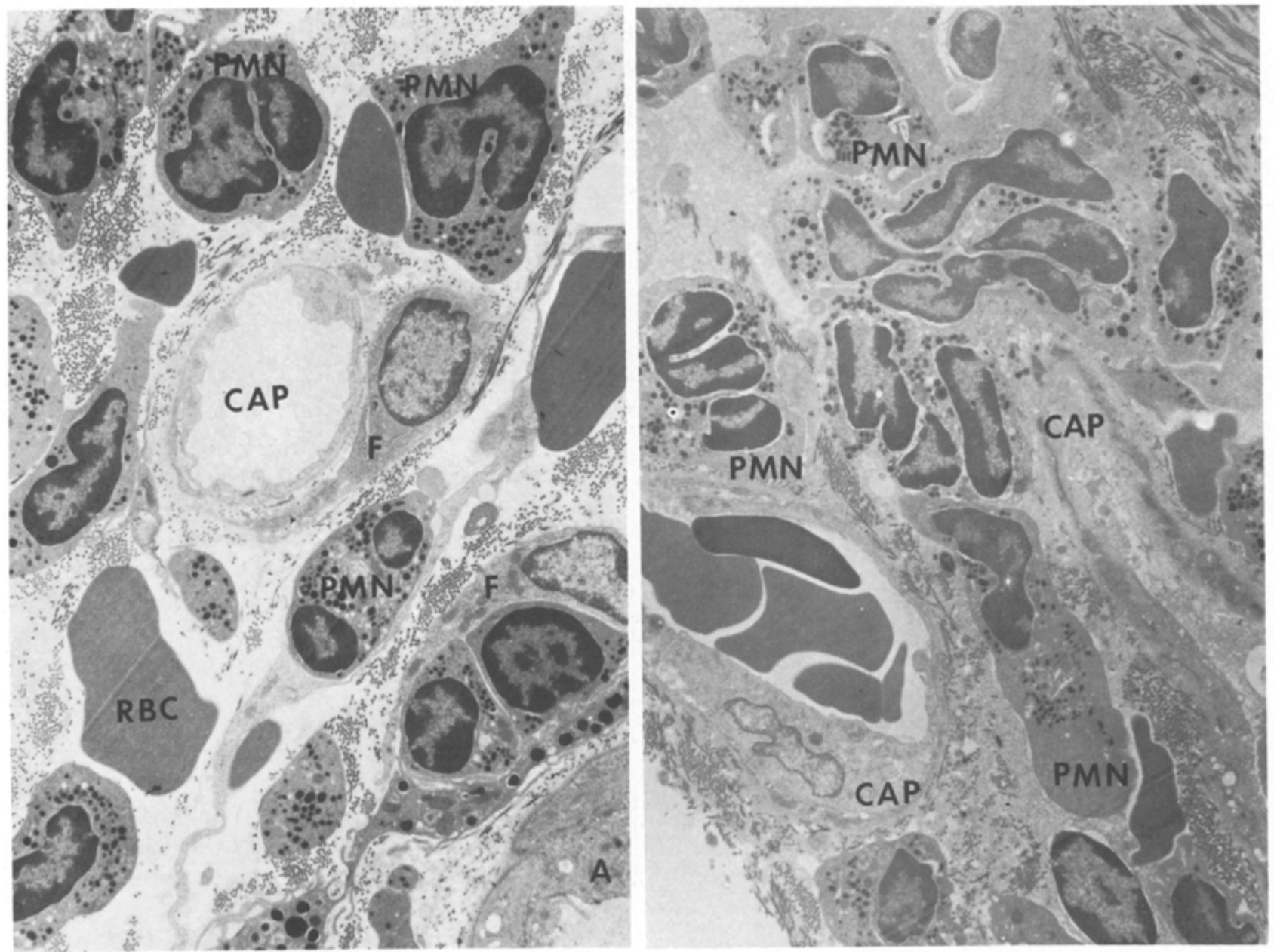

Fig. 5. a Wound from a control hamster $16 \mathrm{~h}$ after injury. Dermal tissue is infiltrated with polymorphonuclear leucocytes $(P M N)$, fibroblasts $(F)$, erythrocytes $(R B C)$ and vascular elements, arteriole $(A)$ and capillary $(C A P) . \times 5,770$. b Wound from a diabetic hamster $16 \mathrm{~h}$ after injury. Degenerating capillaries $(C A P)$ are surrounded by polymorphonuclear leukocytes $(P M N)$ in various stages of degeneration. $\times 6,160$

control hamsters. Fibroblasts, polymorphonuclear leukoytes, macrophages and capillaries were found within the collagen framework. At $16 \mathrm{~h}$, polymorphonuclear leukocytes were clustered at the wound edge in close proximity to the vascular bed (Fig. $5 \mathrm{a}$ ). Many of these capillaries were immature in appearance as defined by irregularity of endothelial cell borders and organisation of cytoplasmic organelles [13, 14]. These "immature" capillaries were frequently observed in both zones 1 and 2 of the control wounds.

\section{Discussion}

This study presents an evaluation of wound healing in normal and diabetic Chinese hamsters. The wound model employed consisted of a small self-limiting wound, in which the wound edge and tissues immediately encircling the area of injury were examined. This is in contrast to other wound models in which relatively large penetrating incisions or implanted artificial chambers are used. The benefit of this model is the ability to examine the sequence of events in the early phase of healing, particularly the initial responses and interactions of the vascular, cellular and extracellular components of the wound.

The ultrastructural appearance of the capillaries in healing wounds from normal and diabetic hamsters was evaluated at 0,8 and $16 \mathrm{~h}$ after injury. In wounds in normal hamsters, minimal changes were observed in the venules $4-8 \mathrm{~h}$ after injury consistent with acute vascular injury [15-18]. Some swelling of the endothelial cells produced a slight increase in vascular permeability probably leading to the mild oedema. There were no alterations in the cytoplasmic organelles of these endothelial cells. By 8 and $16 \mathrm{~h}$, ingrowth of new capillaries appeared through sprouts from the surviving vascular border. Differentiation in 
the type and size of these vessels was determined by the blood flow through their lumen [19] and at this stage they possessed the cytoplasmic characteristics of immature capillaries.

On the other hand, wounds from diabetic hamsters had no proliferating capillaries at any time after injury. Many of the mature capilliaries were observed in various states of degeneration 8 and $16 \mathrm{~h}$ after injury. Injury to the capillaries was irreversible and was marked by stasis, disruption of endothelial cells and cell junctions, fracturing of basement membrane and finally cell necrosis. Such pronounced vascular injury presumably contributed to the oedema of the diabetic wounds, since there was disruption of both capillaries and venules. Thus not only fluids and plasma proteins but also cellular elements found access to the extracellular space, resulting in an increase of red blood cells and polymorphonuclear leukocytes in the $16 \mathrm{~h}$ wounds.

The increased interstitial oedema in the wounds from diabetic hamsters found at the time of injury suggests that accumulation of extracellular fluid may be part of the diabetic syndrome in the Chinese hamster, most likely in response to hyperglycaemia. Evidence to date supports the hypothesis that hyperglycaemia may be associated with sorbitol accumulation and tissue swelling in the lens of the eye, peripheral nerves [20] and smooth muscle and endothelial cells of blood vessels [21]. Swelling of vessel wall components may then contribute to increased vascular permeability followed by loss of fluid into the extracellular space producing more oediema. Although oedema in the tissues of diabetics has not been measured directly, it is clearly a function of increased vascular permeability and plasma volume shifts due to extravasated proteins. The interaction of vascular fragility and permeability and oedema in the impaired response to injury in diabetic tissues is of considerable interest.

It is noteworthy that in some tissues, most notably the cornea and retina, the presence of oedema stimulates a neovascular response which is probably mediated by a diffusable substance in oedema fluid [22]. Increased oedema in wound tissue of diabetic hamsters failed to induce any detectable neovascular response. In fact, by $16 \mathrm{~h}$ after injury, many capillaries and venules had undergone extensive degeneration and necrosis. The endothelial cells appeared to be unresponsive to extracellular vasculogenic factors, perhaps due to lack of receptors for these factors, decreased insulin levels (growth effect of insulin), or persistent hyperglycaemia. In the diabetic wounds an increased plasma shift to the extracellular space may stress the compromised vasculature leading to degeneration and necrosis.
In addition to capillaries and leukocytes, fibroblasts were observed by electron microscopy in the wounds from normal hamsters. No significant increase in fibroblasts was observed consistently in the wounds during the healing period, although the ultrastructural appearance of these cells changed over the $16 \mathrm{~h}$. Many fibroblasts became hypertrophic with an increase and distinct organization of cytoplasmic organelles suggesting protein synthesis and secretion. By contrast, the fibroblasts in healing wounds from diabetic hamsters contained irregularities in the cytoplasm (lysosomes and dense bodies), which are indicative of cells undergoing internal degeneration. This was probably in response to an altered extracellular environment, for example, high glucose, oedema, and low insulin. The appearance of the fibroblasts concomitant with the decrease in collagen in diabetic wounds suggested that the fibroblasts were not responding to injury as observed in control hamsters, but instead were undergoing progressive degeneration. This has been confirmed in other studies where the fibroblast was compromised and unable to synthesise collagen [23-25] and from reports examining the activity of fibroblasts in vitro from diabetic patients [26]. In every instance there was an impaired response to injury with decreased collagen synthesis in vivo and in vitro and shorter life span in vitro [27]. The milieu of the diabetic environment which affects the fibroblasts morphologically and functionally remains to be defined.

The impaired healing response to injury in the spontaneously diabetic Chinese hamster is characterised by a reduction in the vascular, cellular and fibrous elements of wound healing accompanied by increased interstitial oedema. The syndrome in the Chinese hamster shares a common feature with human insulin dependent diabetes, that is, insulinopaenia. Decreased insulin levels not only affect glucose metabolism but probably also suppress a permissive effect of insulin on growth which may lead to impaired wound healing. The results of this study support the hypothesis that insulin is a necessary component for wound healing.

Acknowledgements. We thank Irene Y. Tamai and Brenda McDougall for their technical assistance, Dr. George C. Gerritsen for generously supplying the Chinese hamsters, and Mr. Nickolas Lange for his assistance with the statistical analyses.

This investigation was supported by a research grant from the American Diabetes Association, Southern California Affiliate, and a research grant from the Kroc Foundation.

\section{References}

1. Yerganian GA (1964) Spontaneous diabetes in the Chinese hamster, Cricetulus griseus. IV. Genetic aspects. Ciba Found Symp Endocrinol 15:25-48 
2. Butler L (1967) The inheritance of diabetes in the Chinese hamster. Diabetologia 3: 124-129

3. Gerritsen GC, Blanks MC (1970) Preliminary studies on food and water consumption of prediabetic Chinese hamsters. Diabetologia 6: 177-179

4. Gerritsen GC, Dulin WE (1972) Effect of diet restriction on onset of development of diabetes in prediabetic Chinese hamsters. Acta Diabetol Lat 9:587-613

5. Soret MG, Dulin WE, Mathews J, Gerritsen GC (1974) Morphological abnormalities observed in retina, pancreas and kidney of diabetic Chinese hamsters. Diabetologia 10:567-579

6. Luse SA, Caramia F, Gerritsen GC, Dulin WE (1967) Spontaneous diabetes mellitus in the Chinese hamster: An electron microscopic study of the islets of Langerhans. Diabetologia 3: 97-108

7. McCombs HL, Gerritsen GC, Dulin WE, Chobanian AV (1974) Morphological changes in the aorta of the diabetic Chinese hamsters. Diabetologia 10:601-606

8. Gerritsen GC, Dulin WE (1967) Characterisation of diabetes in the Chinese hamsters. Diabetologia 3: 74-84

9. Arquilla ER, Weringer EJ, Nakajo M (1976) Wound healing: a model for diabetic microangiopathy. Diabetes 25: 811-819

10. Weringer EJ, Kelso JM, Tamai IY, Arquilla ER (1979) Reversal of impaired wound healing in chronic diabetes by insulin. Fed Proc 38: 999

11. Weibel ER, Kistler GS, Scherle WF (1968) Practical steriological methods for morphometric cytology. J Cell Biol 30:23-38

12. Wahl SM, Arend WP, Ross R (1974) The effect of complement depletion on wound healing. Am J Pathol 74: 73-90

13. Schoefl GI (1963) Studies on inflammation. III. Growing capillaries: their structure and permeability. Virchows Arch Pathol Anat 337: 97-141

14. Eriksson E, Zarem HA (1977) Growth and differentiation of blood vessels. In: Kaley G, Altura BM (eds) Microcirculation, vol. 1. University Park Press, p 393-412.

15. Ryan GB, Majno G(1977) Acute inflammation: A review. Am J Pathol 86: 182-276

16. Cotran RS (1965) Delayed and prolonged vascular leakage in inflammation. II. Electron microscope study of the vascular response after thermal injury. Am J Pathol 46:589-620
17. Cotran RS (1967) Delayed and prolonged vascular leakage in inflammation. III. Immediate and delayed vascular reactions in skeletal muscle. Exp Mol Pathol 6: 143-155

18. Cotran RS, Remensynder JP (1968) The structural basis of increased vascular permeability after graded thermal injury: Light and electron microscopic studies. Ann NY Acad Sci 150: 495-509

19. Schoefl GI (1964) Electron microscope observation of the regeneration of blood vessels after injury. Ann NY Acad Sci 116: 789-802

20. Gabbay K (1973) The sorbitol pathway and the complications of diabetes. N Engl J Med 288: 831-836

21. Rasio E, Morrison AD, Winegrad AI (1972) Demonstration of polyol pathway activity in an isolated capillary preparation. Diabetes $21: 330-336$

22. Ben Ezra D (1978) Neovasculogenic ability of prostaglandins, growth factors and synthetic chemoattractants. Am J Ophthalmol 86: 445-461

23. Ross R, Benditt EP (1964) Wound healing and collagen formation. IV. Distortion of ribosomal patterns of fibroblasts in scurvy. J Cell Biol 22:365-389

24. Grillo HC, Gross J (1967) Collagenolytic activity during mammalian wound repair. Dev Biol 15:300-317

25. Priest RE (1972) Cellular replication and specialized function of fibroblasts. J Invest Dermatol 59:35-39

26. Goldstein S, Littlefield JW, Soeldner JS (1969) Diabetes mellitus and aging: diminished plating efficiency of cultured human fibroblasts. Proc Natl Acad Sci USA 64: 155-160

27. Rosenbloom AL (1978) Insulin-dependent childhood diabetes. Normal viability of cultured fibroblasts. Diabetes $27: 338-341$

Received: 10 March 1980

and in revised form: 18 May 1981

Elora J. Weringer, Ph. D.

Department of Pathology

University of Massachusetts Medical Center

55 Lake Avenue, North

Worcester, MA 01605, USA 